\title{
RELEASES OF DANGEROUS CHEMICALS IN POLAND IN 2005 IN THE CONTEXT OF THE HAZARDOUS SUBSTANCES EMERGENCY EVENTS SURVEILLANCE (HSEES) SYSTEM DEVELOPED IN THE US
}

\author{
ANNA PALASZEWSKA-TKACZ \\ Nofer Institute of Occupational Medicine, Łódź, Poland \\ Scientific Information Department
}

\begin{abstract}
Objectives: To present a dataset concerning acute releases of hazardous chemicals in Poland in 2005 in the context of the HSEES system implemented in Poland. Material and Methods: ATSDR, as the coordinator of the HSEES system, determined the kind and scope of data to be collected. In Poland, the fire department's reports were the main source of information on chemical emergencies. Results: In 2005, as many as 245 incidents of chemical release and 23 of threatened release were recorded. Most of acute chemical incidents were associated with transportation and warehousing $(106 ; 39.6 \%)$; in this truck transportation accounted for almost $50 \%$, and the chemical and food sector for a little more than $50 \%$ of the total incidents. Human error and equipment failure were the primary causal factors, contributing respectively to 147 (54.9\%) and 103 (38.4\%) incidents. The chemicals involved most frequently were mercury (21.4\%), propane-butane mixture (9.7\%), ammonia (7.1\%), hydrochloric acid, natural gas, sulfuric acid (5.2-5.6\%) and nitric acid (5.2\%). Out of 268 emergencies, 43 (16.0\%) involved casualties: 191 in total, including $180(94.2 \%)$ in the fixed facility incidents and $11(5.8 \%)$ in the transportation-related incidents. The largest group of casualties were students (97) followed by employees (62). The most common injury related to chemical emergency was respiratory irritation $(142 ; 74.3 \%)$. Conclusions: The database on acute chemical emergencies in Poland, based on the HSEES system, makes it possible to generate a variety of statistical analyses that are helpful in planning effective prevention activities to diminish the harmful effects of such incidents.
\end{abstract}

Key words:

Chemical emergency, Firefighters, Prevention, Hazardous substances

\section{INTRODUCTION}

The Hazardous Substances Emergency Events Surveillance (HSEES) system was established by the Agency for Toxic Substances and Diseases Registry (ATSDR) in 1990 with the aim of collecting and analyzing information about acute releases and threatened releases of hazardous substances that result in a public health action such as an evacuation. The main goal of the HSEES is to reduce the rate of chemical emergency-related injuries and deaths among the first responders, employees, and general public. The set of data collected and analyzed in such an intended and unique configuration is a useful tool in developing plans of prevention activities aimed at public health protection. The activities in question consist mostly in providing the responders, industry, and general public with information on how to avoid releases of dangerous chemicals and how to reduce the possible harmful effects of such incidents [1].

Among the databases operated in Poland there is none that would strictly regard the releases of dangerous chemicals and the related health effects. Consequently, the chemical emergency response system in Poland lacks the data analysis that could be helpful in this respect. Therefore, the implementation of the American HSEES system in

Received: July 11, 2008. Accepted: November 12, 2008.

Address reprint requests to A. Pałaszewska-Tkacz, Scientific Information Department, Nofer Institute of Occupational Medicine, ul. Teresy 8, 91-348 Łódź, Poland (e-mail: apalasz@imp.lodz.pl). 
Poland, which was initiated in September 2004 by signing an agreement between ATSDR and NIOM, and also with the Polish Fire Department Headquarters, was a crucial step in establishing this database. Moreover, one of its outcomes was a technical report on the 2005 dataset on acute chemical emergencies in Poland that has been summarized in the present article.

\section{MATERIALS AND METHODS}

The development of any database requires identifying and getting access to reliable sources of data, defining the kind and scope of data to be collected, and designating relevant software. In the US, acute releases of hazardous substances are reported to appropriate state health departments by various authorities responsible for notification including state environmental protection agencies, the US Department of Transportation, the National Response Center, police, fire departments, and hospitals. The reported cases are analyzed and entered into the database by a qualified staff [2]. In Poland, the fire department, as the service responding to practically all chemical emergency incidents, is the most reliable and accurate source of information. The firefighters who are involved in chemical emergency response are also obliged to report on their actions. A brief description of the accident is made onsite and then forwarded at first to the district and finally to the national headquarters of the Fire Service. After securing personal data, the reports on chemical emergencies are passed to NIOM which handles data collection, management and analysis that are the components of the surveillance system, as well as prepares technical reports aimed at developing effective strategies to reduce the morbidity and mortality related to chemical accidents.

The hazardous substances emergency events are defined by HSEES as acute uncontrolled/illegal releases or threatened ${ }^{1}$ releases of hazardous substances [2]. The incidents of petroleum release are not considered. The chemical emergencies reported to HSEES in 2005 included releases

\footnotetext{
1 Threatened release - the release of a substance that did not actually occur, but the threat of which led to an action (e.g. evacuation) aimed at health protection of employees, emergency responders, or general public.
}

of substances in a different chemical state, but a majority of them involved liquids. The spills reported took place in different kinds of environment, including working environment and practically all environmental media. The chemical emergency events captured by HSEES are classified according to whether they occurred at fixed facilities or during transportation. The fixed-facility events involve hazardous substances released at industrial sites, schools, farms, or other permanent facilities, and the transportation-related events involve hazardous materials released during transport by surface, air, or water.

The electronic data entry system (HSEES software, version 4.0) is a web-based application that provides a simple method for entering data into a centralized computer database. Using the web-based system ensures that there is only one version of the data entry screen, which facilitates the changes and updates of the records. This solution prevents the duplication of the reports entered as well as entering different descriptions of the same event. Each event has a unique, sequential identification number (ID) which is generated by the software each time a new event is entered. Updated information about the event can be added by re-opening a particular event ID. The HSEES application is designed to leave little room for misinterpretation. Practically any type of information describing the event may be chosen from a specific pick list, such as a substance or industry pick list. The scope of data to be collected is also specified in detail and includes [2]:

- Event identification and notification information,

- Time, date, and day of the week of the event,

- Event description,

- Event type (fixed-facility or transportation-related event),

- Geographical location and place within the facility where the event occurred,

- Factors contributing to the release,

- Substance chemical or trade name,

- Specific information on injured persons: age, sex, type and extent of injuries, distance from spill, population group (employee, general public, responder, student), and type of protective equipment used, 
- Information about decontaminations, orders to evacuate or shelter-in-place,

- Land use and population information to estimate the number of persons at home or work who were potentially exposed,

- Response to and termination of the event.

An analysis of the data collected in Poland in 2005 formed grounds for preparing a final report with detailed descriptions of acute chemical releases. The results helped to develop the first aid algorithms for firefighters as the main responding group in chemical accidents.

\section{RESULTS}

\section{Types of events}

In Poland in 2005, a total of 268 events concordant with the HSEES definition were reported and eligible for loading into the database. A total of 164 (61.2\%) events occurred in fixed facilities and 104 (38.8\%) events were connected with the transportation of dangerous chemicals. The largest number of chemical emergencies in general was recorded in the following administrative districts (voivodships): Śląskie (46; 17.2\%), Mazowieckie $(32 ; 11.9 \%)$ and Dolnośląskie (31; 11.6\%). The fixed-facility events were most frequent also in Śląskie $(35,17.2 \%)$ and Mazowieckie (22; 13.4\%) while the transportation-related events in Dolnośląskie (16; 15.4\%), Śląskie $(11 ; 10.6 \%)$ and in Mazowieckie and Pomorskie (10;9.6\%). No fixed-facility events and only one transportation-related event were noted in Zachodniopomorskie. Table 1 presents the rate of events by type and administrative district of Poland.

Data analysis by the type of transport revealed that of all the 104 transportation-related events, 62 (59.6\%) referred to ground (road) transport, $26(25.0 \%)$ to rail transport and $14(13.5 \%)$ to the pipeline supply system (Table 2). The largest number of chemical emergency events related to ground transportation was associated with the moving vehicles (37) and stationary vehicles (24). Fewer events

Table 1. Chemical emergencies, by type of event and administrative district, Poland, 2005

\begin{tabular}{llrrrrrrr}
\hline & & \multicolumn{3}{c}{ Type of event } & & \multirow{2}{*}{ Total } \\
\cline { 3 - 6 } & & \multicolumn{2}{c}{ Fixed-facility } & Transportation-related & & \\
\cline { 3 - 6 } & & No. events & $\%^{*}$ & No. events & $\%^{*}$ & No. events & $\%$ \\
\hline Śląskie & SL & 35 & 21.3 & 11 & 10.6 & 46 & 17.2 \\
Mazowieckie & MA & 22 & 13.4 & 10 & 9.6 & 32 & 11.9 \\
Dolnośląskie & DS & 15 & 9.1 & 16 & 15.4 & 31 & 11.6 \\
Malopolskie & MP & 17 & 10.4 & 8 & 7.7 & 25 & 9.3 \\
Pomorskie & PM & 13 & 7.9 & 10 & 9.6 & 23 & 8.6 \\
Lódzkie & LD & 16 & 9.8 & 6 & 5.8 & 22 & 8.2 \\
Kujawsko-Pomorskie & KP & 10 & 6.1 & 6 & 5.8 & 16 & 6.0 \\
Wielkopolskie & WP & 9 & 5.5 & 6 & 5.8 & 15 & 5.6 \\
Podlaskie & PD & 5 & 3.0 & 8 & 7.7 & 13 & 4.9 \\
Lubelskie & LU & 4 & 2.4 & 7 & 6.7 & 11 & 4.1 \\
Warmińsko-Mazurskie & WM & 7 & 4.3 & 1 & 1.0 & 8 & 3.0 \\
Lubuskie & LB & 5 & 3.0 & 2 & 1.9 & 7 & 2.6 \\
Świętokrzyskie & SW & 4 & 1.2 & 3 & 4.8 & 7 & 2.6 \\
Podkarpackie & PK & 2 & 2.4 & 5 & 2.9 & 7 & 2.6 \\
Opolskie & OP & 0 & 0.0 & 4 & 3.8 & 4 & 1.5 \\
Zachodniopomorskie & ZP & 0 & 0.0 & 1 & 1.0 & 1 & 0.4 \\
Total & & 164 & 100.0 & 104 & 100.0 & 268 & 100.0 \\
\hline
\end{tabular}

* Number of events in administrative district, by type of event, to total number of events of this type in Poland $\times 100$. 
Table 2. Transportation-related events, by transportation phase and type, Poland, 2005

\begin{tabular}{lccccc}
\hline \multirow{2}{*}{ Transport type } & $\begin{array}{c}\text { No. } \\
\text { events }\end{array}$ & $\%$ & $\begin{array}{c}\text { Unloading of a stationary } \\
\text { vehicle/vessel }\end{array}$ & Moving vehicle/vessel & Stationary vehicle/vessel \\
\hline Ground (road) & 62 & 59.6 & 5 & 37 & 20 \\
Rail & 26 & 25.0 & 1 & 1 & 24 \\
Pipeline & 14 & 13.5 & 0 & 0 & 14 \\
Water & 2 & 1.90 & 0 & 38 & 2 \\
Total & 104 & 100 & 6 & & 30 \\
\hline
\end{tabular}

Table 3. HSEES events in different surroundings at accident site, by type of event, Poland, 2005

\begin{tabular}{|c|c|c|c|c|c|c|}
\hline \multirow{3}{*}{ Surroundings at accident site } & \multicolumn{4}{|c|}{ Type of event } & \multicolumn{2}{|c|}{ Total* $^{*}$} \\
\hline & \multicolumn{2}{|c|}{ Fixed-facility } & \multicolumn{2}{|c|}{ Transportation-related } & \multirow{2}{*}{ No. events } & \multirow{2}{*}{$\%$} \\
\hline & No. events & $\%$ & No. events & $\%$ & & \\
\hline Residential area & 125 & 68.3 & 68 & 57.1 & 193 & 63.9 \\
\hline Industrial area & 33 & 18.0 & 17 & 14.3 & 50 & 16.6 \\
\hline Agricultural area & 11 & 6.0 & 22 & 18.5 & 33 & 10.9 \\
\hline Undeveloped area & 1 & 0.5 & 7 & 5.9 & 8 & 2.6 \\
\hline Commercial area & 6 & 3.3 & 2 & 1.7 & 8 & 2.6 \\
\hline Recreational area & 5 & 2.7 & 2 & 1.7 & 7 & 2.3 \\
\hline Military facility/DOE/DOD & 2 & 1.1 & 1 & 0.8 & 3 & 1.0 \\
\hline Total* & 183 & 100.0 & 119 & 100.0 & 302 & 100.0 \\
\hline
\end{tabular}

* Total no. of events $>268$ - some events occurred in mixed type areas.

pertained to water transportation and no event of this kind was recorded in air transport (Table 2).

\section{Time and place of events}

The largest number of hazardous substance releases occurred in residential areas: 193 (63.9\%) events in

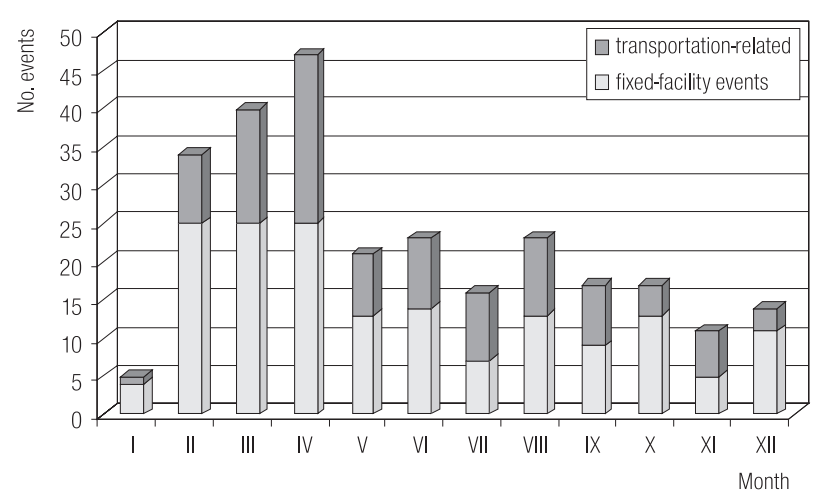

Fig. 1. Number of HSEES events, by type and time of occurrence (month), Poland, 2005. total, including 125 (68.3\%) fixed-facility events and 68 (57.1\%) transportation-related events. As regards the fixed-facility events, a relatively high number $(33 ; 18.0 \%)$ took place in industrial settings, and among the transportation-related events, 22 (18.5\%) occurred in agricultural areas (Table 3).

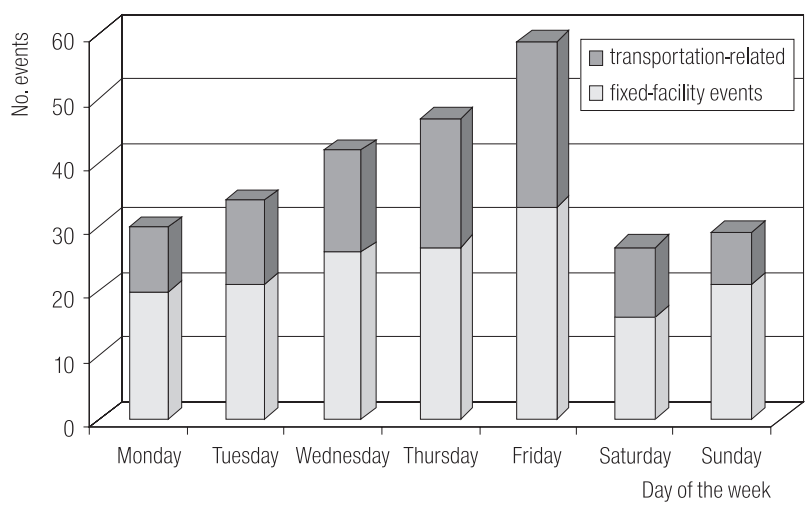

Fig. 2. Number of HSEES events, by type and time of occurrence (day of the week), Poland, 2005. 


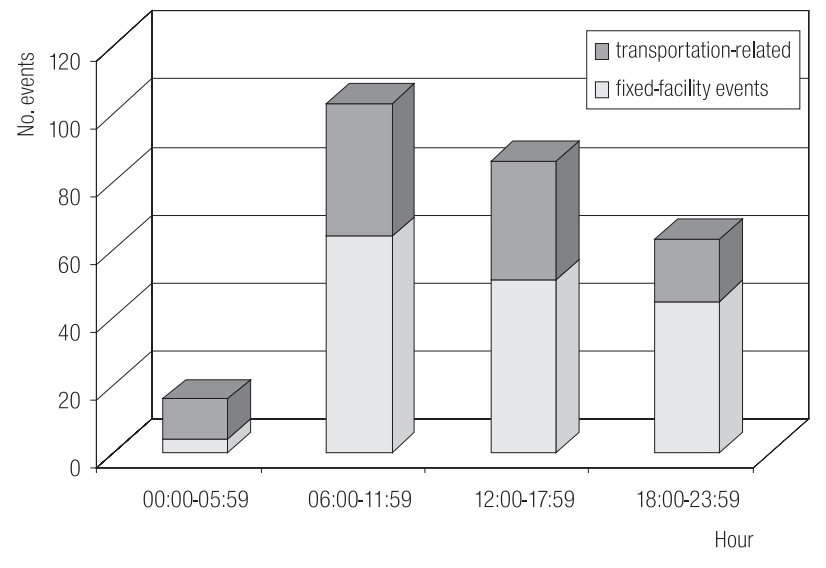

Fig. 3. Number of HSEES events, by type and time of occurrence (hour), Poland, 2005.

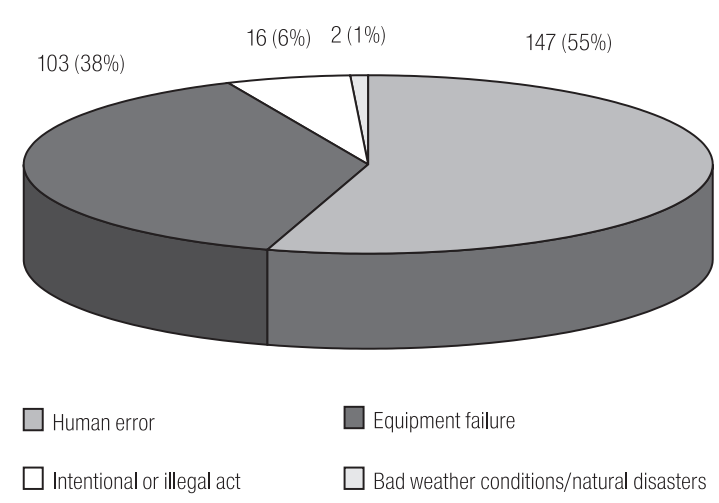

Fig. 4. Primary causal factors of chemical emergencies, Poland 2005.

Data analysis by the time of event, with the month, the day of the week and the time of day as the time-points, revealed that the highest frequency of chemical emergencies was noted in February $(34 ; 12.7 \%)$, March $(40 ; 14.9 \%)$ and April (47; 17.5\%), as well as on Fridays $(59 ; 22 \%)$ and the hours between $6: 00$ am and noon $(103 ; 38.4 \%)$ (Fig. 1-3).

\section{Causal factors}

The major factor contributing to chemical emergency incidents was human error which referred both to the fixed-facility (83) and transportation-related (64) events and was the primary cause of 147 (54.9\%) events in total. Equipment failure accounted for 103 (38.4\%) events, including 68 fixed-facility and 35 transportation-related events (Fig. 4).

\section{Industries and services involved}

As presented in Table 4, transportation and warehousing was the sector with the largest number of chemical spills $(106 ; 39.6 \%)$ and manufacturing was ranked third $(38 ; 14.2 \%)$. A relatively high number of releases in other services were connected mainly with household events, these including mercury release from broken thermometers. Within the transportation and warehousing sector, the truck transportation accounted for almost $50 \%$ of the events, and in the manufacturing sector, the chemical and food industry for over $50 \%$ of the events. The events involving casualties were also most frequent in the transportation and warehousing (11) and in manufacturing (10). On the other hand, the highest number of injury cases was recorded in the educational services (schools) (102) and in manufacturing (37) (Table 4).

\section{Chemicals}

Almost all the events reported (254; 94.8\%) involved a release of a single substance: 155 (94.5\%) fixed-facility events and 99 (95.2\%) transportation-related events. Multiple chemicals were released only in 14 events. In total, 121 different substances were involved in chemical emergency incidents: 79 in fixed-facility events and 56 in transportation-related events (Table 5).

The chemicals released most frequently included mercury $(21.4 \%)$, propane-butane mixture $(9.7 \%)$, ammonia $(7.1 \%)$, hydrochloric acid, natural gas, sulfuric acid (5.2-5.6\%) and nitric acid (4.1\%) (Table 6).

For the HSEES purposes, the chemicals were divided into 12 categories. Table 7 displays the results of analysis by the number and type of events in particular chemical categories. For the 20 most common substances, NIOM worked out the first aid algorithms which were forwarded to the fire department as the main responder in HSEES events. The algorithms were developed for mercury diiodide (CAS 7774-29-0), potassium dichromate (CAS 7778-50-9), hydrogen sulphide (CAS 7783-06-4), ethylene oxide (CAS 7521-8), chlorine (CAS 7782-50-5), hydrogen chloride (CAS 7647-01-0), formaldehyde (CAS 50-00-0), aluminium phosphide (CAS 20859-73-8), phenol (CAS 108-95-2), hydrazine (CAS 302-01-2), sodium hydroxide (CAS 1310-73-2), 
Table 4. Industries and services involved in chemical emergency incidents, Poland, 2005

\begin{tabular}{lcccc}
\hline \multicolumn{1}{c}{ Industry/service } & Total no. events & $\%$ & $\begin{array}{c}\text { No. casualty } \\
\text { events }\end{array}$ & $\begin{array}{c}\text { Total no. } \\
\text { casualties }\end{array}$ \\
\hline Transportation and Warehousing & 106 & 39.6 & 11 & 20 \\
Other Services (except Public Administration) & 74 & 27.6 & 9 & 20 \\
Manufacturing & 38 & 14.2 & 10 & 37 \\
Administrative and Support, and Waste Management and & 13 & 4.9 & 3 & 4 \\
$\quad$ Remediation Services & & & & \\
Educational Services & 13 & 4.9 & 6 & 102 \\
Construction & 6 & 2.2 & 1 & 1 \\
Utilities & 4 & 1.5 & 0 & 0 \\
Health Care and Social Assistance & 3 & 1.1 & 0 & 0 \\
Arts, Entertainment, and Recreation & 3 & 1.1 & 1 & 1 \\
Accommodation and Food Services & 3 & 1.1 & 2 & 6 \\
Agriculture & 2 & 0.7 & 0 & 0 \\
Professional, Scientific, and Technical Services & 1 & 0.4 & 0 & 0 \\
Management of Companies and Enterprises & 1 & 0.4 & 0 & 0 \\
Unspecified or unknown & 1 & 0.4 & 0 & 0 \\
Total & 268 & 100.0 & 43 & 191 \\
\hline
\end{tabular}

Table 5. Chemicals involved per event, by type of event, Poland, 2005

\begin{tabular}{|c|c|c|c|c|c|c|c|c|c|}
\hline \multirow{3}{*}{$\begin{array}{c}\text { No. } \\
\text { chemicals } \\
\text { involved }\end{array}$} & \multicolumn{6}{|c|}{ Type of event } & \multirow{2}{*}{\multicolumn{3}{|c|}{ All events }} \\
\hline & \multicolumn{3}{|c|}{ Fixed-facility } & \multicolumn{3}{|c|}{ Transportation-related } & & & \\
\hline & No. events & $\%$ & $\begin{array}{c}\text { Total } \\
\text { chemicals } \\
\text { involved }\end{array}$ & No. events & $\%$ & $\begin{array}{c}\text { Total } \\
\text { chemicals } \\
\text { involved }\end{array}$ & No. events & $\%$ & $\begin{array}{c}\text { Total } \\
\text { chemicals } \\
\text { involved }\end{array}$ \\
\hline 1 & 155 & 94.5 & 55 & 99 & 95.2 & 46 & 254 & 94.8 & 101 \\
\hline 2 & 5 & 3.0 & 10 & 3 & 2.9 & 5 & 8 & 3.0 & 15 \\
\hline 3 & 1 & 0.6 & 3 & 1 & 1.0 & 3 & 2 & 0.7 & 6 \\
\hline$\geq 4$ & 3 & 1.8 & 19 & 1 & 1.0 & 5 & 4 & 1.5 & 24 \\
\hline Total & 164 & 100.0 & 79 & 104 & 100.0 & 56 & 268 & 100.0 & 121 \\
\hline
\end{tabular}

Table 6. Chemicals released most frequently, by number of events, Poland, 2005

\begin{tabular}{llcr}
\hline \multicolumn{2}{c}{ Substance (CAS No.) } & $\begin{array}{c}\text { No. } \\
\text { events }\end{array}$ & $\%$ \\
\hline Mercury & $(7439-97-6)$ & 57 & 21.4 \\
Propane-butane mix. 70\% & $(68512-91-4)$ & 26 & 9.7 \\
Ammonia & $(7664-41-7)$ & 19 & 7.1 \\
Hydrochloric acid & $(7647-01-0)$ & 15 & 5.6 \\
Natural gas & $(8006-14-2)$ & 14 & 5.2 \\
Sulfuric acid & $(7664-93-9)$ & 14 & 5.2 \\
Nitric acid & $(7697-37-2)$ & 11 & 4.1 \\
\hline
\end{tabular}

acetic acid (CAS 64-19-7), nitric acid (CAS 7697-37-2), sulphuric acid (CAS 7664-93-9), orthophosphoric acid (CAS 7664-38-2), hydrogen chloride (WE 231-595-7), butyric acid (CAS 107-92-6), sodium hypochlorite (CAS 7681-52-9), calcium hypochlorite (CAS 7778-54-3), ammonia, aqueous solution (CAS 1336-21-6).

\section{Casualties}

Of the total number of 268 chemical emergencies, $43(16 \%)$ involved casualties: 191 in total, including 180 (94.2\%) in 34 fixed-facility events and 11 (5.8\%) in 9 transportation- 
Table 7. Chemicals involved in HSEES events, by chemical category and type of event, Poland, 2005

\begin{tabular}{lcccccc}
\hline \multirow{2}{*}{ Chemical category } & \multicolumn{7}{c}{ Type of event } \\
\cline { 2 - 7 } & \multicolumn{7}{c}{ Fixed-facility } & \multicolumn{4}{c}{ Transportation-related } \\
\cline { 2 - 7 } & No. chemicals & $\%$ & No. events & No. chemicals & $\%$ & No. events \\
\hline Acids & 10 & 12.7 & 27 & 5 & 8.9 & 21 \\
Ammonia & 2 & 2.5 & 12 & 1 & 1.8 & 7 \\
Bases & 5 & 6.3 & 6 & 4 & 7.1 & 9 \\
Chlorine & 3 & 3.8 & 8 & 1 & 1.8 & 1 \\
Hetero-organics & 1 & 1.3 & 1 & 0 & 0.0 & 0 \\
Hydrocarbons & 1 & 1.3 & 1 & 6 & 10.7 & 8 \\
Other inorganic substances & 20 & 25.3 & 76 & 6 & 10.7 & 7 \\
Oxy-organics & 11 & 13.9 & 18 & 4 & 7.1 & 4 \\
Paints and dyes & 1 & 1.3 & 1 & 1 & 1.8 & 1 \\
Pesticides & 3 & 3.8 & 3 & 6 & 10.7 & 6 \\
Polymers & 1 & 1.3 & 1 & 2 & 3.6 & 2 \\
VOCs & 7 & 8.9 & 14 & 10 & 17.9 & 32 \\
Mixtures & 1 & 1.3 & 1 & 3 & 5.4 & 3 \\
Other & 13 & 16.4 & 16 & 7 & 12.5 & 15 \\
Total & 79 & 100.0 & - & 56 & 100.0 & - \\
\hline
\end{tabular}

Table 8. Casualty events, by type of event and administrative district, Poland, 2005

\begin{tabular}{|c|c|c|c|c|c|c|c|c|}
\hline \multirow{3}{*}{ District } & \multicolumn{6}{|c|}{ Type of event } & \multirow{3}{*}{ Total events } & \multirow{3}{*}{$\begin{array}{c}\text { Total } \\
\text { casualty } \\
\text { events }(\% *)\end{array}$} \\
\hline & \multicolumn{3}{|c|}{ Fixed-facility } & \multicolumn{3}{|c|}{ Transportation-related } & & \\
\hline & No. events & $\begin{array}{l}\text { No. casualty } \\
\text { events }\end{array}$ & $\% *$ & No. events & $\begin{array}{l}\text { No. casualty } \\
\text { events }\end{array}$ & $\% *$ & & \\
\hline Mazowieckie & 22 & 8 & 36.4 & 10 & 0 & 0.0 & 32 & $8(25.0)$ \\
\hline Śląskie & 35 & 5 & 14.3 & 11 & 2 & 18.2 & 46 & $7(15.2)$ \\
\hline Świętokrzyskie & 4 & 3 & 75.0 & 3 & 1 & 33.3 & 7 & $4(57.1)$ \\
\hline Kujawsko-Pomorskie & 10 & 4 & 40.0 & 6 & 0 & 0.0 & 16 & $4(25.0)$ \\
\hline Łódzkie & 16 & 4 & 25.0 & 6 & 0 & 0.0 & 22 & $4(18.2)$ \\
\hline Dolnośląskie & 15 & 3 & 20.0 & 16 & 0 & 0.0 & 31 & $3(9.7)$ \\
\hline Małopolskie & 17 & 1 & 5.9 & 8 & 2 & 25.0 & 25 & $3(12.0)$ \\
\hline Pomorskie & 13 & 2 & 15.4 & 10 & 0 & 0.0 & 23 & $2(8.7)$ \\
\hline Lubuskie & 5 & 2 & 40.0 & 2 & 0 & 0.0 & 7 & $2(28.6)$ \\
\hline Warmińsko-Mazurskie & 7 & 2 & 28.6 & 1 & 0 & 0.0 & 8 & $2(25.0)$ \\
\hline Podlaskie & 5 & 0 & 0.0 & 8 & 2 & 25.0 & 13 & $2(15.4)$ \\
\hline Podkarpackie & 2 & 0 & 0.0 & 5 & 1 & 20.0 & 7 & $1(14.3)$ \\
\hline Zachodniopomorskie & 0 & 0 & 0.0 & 1 & 1 & 100.0 & 1 & $1(100.0)$ \\
\hline Wielkopolskie & 9 & 0 & 0.0 & 6 & 0 & 0.0 & 15 & $0(0.0)$ \\
\hline Lubelskie & 4 & 0 & 0.0 & 7 & 0 & 0.0 & 11 & $0(0.0)$ \\
\hline Opolskie & 0 & 0 & 0.0 & 4 & 0 & 0.0 & 4 & $0(0.0)$ \\
\hline Total & 164 & 34 & 20.7 & 104 & 9 & 8.7 & 268 & $43(16.0)$ \\
\hline
\end{tabular}

* Ratio of the number of casualty events per administrative district to the total number of events in this district $\times 100$. 
Table 9. Casualty events, by type of event and administrative district, Poland, 2005

\begin{tabular}{lcccccc}
\hline \multirow{2}{*}{ District } & \multicolumn{2}{c}{ Fixed-facility events } & Transportation-related events & \multicolumn{2}{c}{ Total } \\
\cline { 2 - 6 } & $\begin{array}{c}\text { No. casualty } \\
\text { events }\end{array}$ & No. casualties & $\begin{array}{c}\text { No. casualty } \\
\text { events }\end{array}$ & No. casualties & $\begin{array}{c}\text { No. casualty } \\
\text { events }\end{array}$ & $\begin{array}{c}\text { No. casualties } \\
(\%)\end{array}$ \\
\hline Lódzkie & 4 & 54 & 0 & 0 & 4 & $54(28.3)$ \\
Świętokrzyskie & 3 & 40 & 1 & 1 & 4 & $41(21.5)$ \\
Mazowieckie & 8 & 35 & 0 & 0 & 8 & $35(18.3)$ \\
Śląskie & 5 & 9 & 2 & 2 & 7 & $11(5.8)$ \\
Dolnośląskie & 3 & 11 & 0 & 0 & 3 & $11(5.8)$ \\
Kujawsko-Pomorskie & 4 & 10 & 0 & 0 & 4 & $10(5.2)$ \\
Warmińsko-Mazurskie & 2 & 9 & 0 & 0 & 2 & $9(4.7)$ \\
Lubuskie & 2 & 8 & 0 & 0 & 2 & $8(4.2)$ \\
Malopolskie & 1 & 1 & 2 & 2 & 3 & $3(1.6)$ \\
Pomorskie & 2 & 3 & 0 & 0 & 2 & $3(1.6)$ \\
Podlaskie & 0 & 0 & 2 & 2 & 2 & $2(1.0)$ \\
Podkarpackie & 0 & 0 & 1 & 2 & 1 & $2(1.0)$ \\
Zachodniopomorskie & 0 & 0 & 1 & 2 & 1 & $2(1.0)$ \\
Wielkopolskie & 0 & 0 & 0 & 0 & 0 & $0(0.0)$ \\
Lubelskie & 0 & 0 & 0 & 0 & 0 & $0(0.0)$ \\
Opolskie & 0 & 0 & 0 & 0 & 0 & $0(0.0)$ \\
Total & 34 & 180 & 9 & 11 & 43 & $191(100.0)$ \\
\hline
\end{tabular}

related events. Mazowieckie and Śląskie were the districts with the largest number of casualty events, and Wielkopolskie, Lubelskie and Opolskie had no records of such events (Table 8).

In the 43 events, 191 victims were reported: 180 (94.2\%) in fixed-facility events and 11 (5.8\%) in transportation-related events. In total, the highest number of victims in chemi-

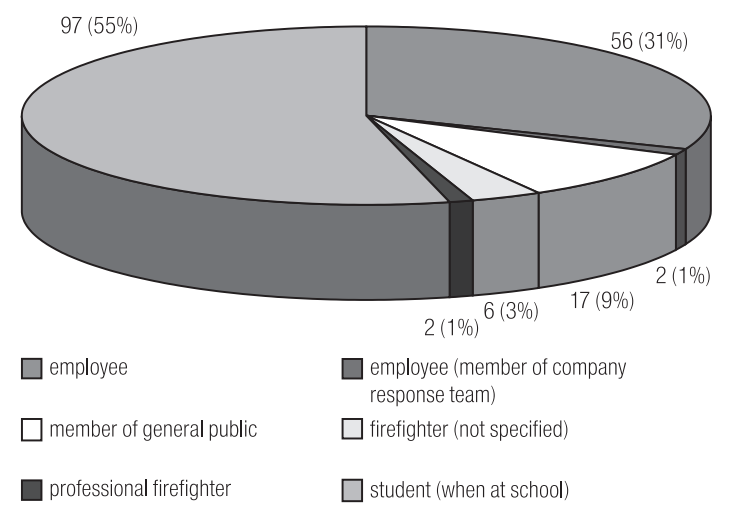

Fig. 5. Number of casualties in fixed-facility events, by casualty category, Poland, 2005.

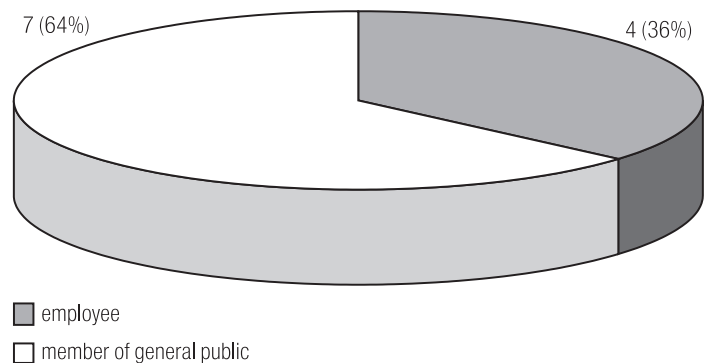

Fig. 6. Number of casualties in transportation-related events, by casualty category, Poland, 2005.

cal accidents was reported in Łódzkie (54), Świętokrzyskie (41) and Mazowieckie (35) (Table 9).

The largest group of casualties were students (97); this was mostly due to a significant number of victims (48) in an incident of pepper gas release by a junior high school student. The casualties suffering from stomach ache, dizziness, nausea, sore throat, cough, and eye irritation were transported to hospital for observation.

There were also 62 (32.5\%) casualties among employees, these including 58 in fixed-facility events and 4 in transportation-related events (Figures 5-7). 


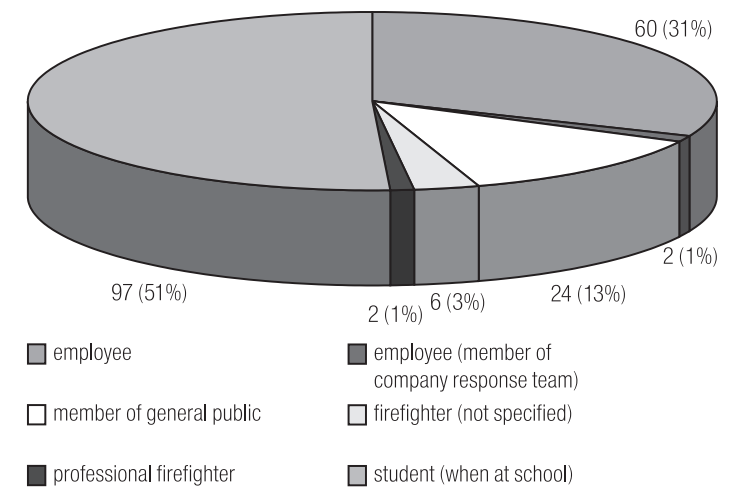

Fig. 7. Number of casualties, in chemical emergencies in total, by casualty category, Poland, 2005.

Among the effects of exposure connected with chemical incidents, respiratory irritation prevailed: it was reported by $142(74.3 \%)$ individuals, including 93 students, 33 employees, 15 members of the general public and 1 firefighter. Gastrointestinal problems and headache were reported by over $40 \%$, eye irritation by almost $32 \%$, and dizziness or other CNS problems by almost $30 \%$ of the injured (Table 10).

\section{Evacuation}

An official evacuation order was issued in 49 events (18.3\%). The reports describing 39 events which involved evacuation (79.6\% of all evacuations) reveal that the
Table 11. Number of evacuations in chemical emergencies (official records), Poland, 2005

\begin{tabular}{lcc}
\hline \multicolumn{1}{c}{ No. people evacuated } & No. events & $\%$ \\
\hline$<5$ & 6 & 12.2 \\
$5-20$ & 12 & 24.5 \\
$21-50$ & 7 & 14.3 \\
$51-100$ & 6 & 12.2 \\
$101-500$ & 12 & 24.5 \\
$500-1000$ & 5 & 10.2 \\
$>1000$ & 1 & 2.1 \\
Total & 49 & 100.00 \\
\hline
\end{tabular}

number of evacuated people ranged from 1-1140 people, with a median of 30 people (Table 11).

The majority of evacuations (65.3\%) concerned the building(s) or the affected part of the building(s). In other defined evacuation areas of a circle/radius or downwind/downstream, the evacuation order was issued only in 7 events (14.3\%). In other cases, the evacuation area was not defined or no information was available (Table 12).

In 114 events (42.5\%), the responders declared the affected area to be restricted. The restrictions most frequently referred to an access route or road (38 events, 14.2\%). The rates of events with restricted access to a room, wing

Table 10. Injuries resulting from chemical accidents, by number and casualty category, Poland, 2005

\begin{tabular}{lrrrrrrr}
\hline & \multicolumn{7}{c}{ Casualty category* } \\
\cline { 2 - 7 } \multicolumn{1}{c}{ Injury type } & 1 & 2 & 3 & 4 & 5 & 6 & Total (\%) \\
\cline { 2 - 7 } & 33 & 15 & 1 & 0 & 0 & 93 & $142(74.3)$ \\
\hline Respiratory irritation & 1 & 2 & 0 & 0 & 0 & 81 & $84(44.0)$ \\
Gastrointestinal problem & 1 & 0 & 0 & 0 & 0 & 82 & $83(43.5)$ \\
Headache & 14 & 0 & 0 & 0 & 0 & 47 & $61(31.9)$ \\
Eye irritation & 16 & 5 & 0 & 0 & 0 & 35 & $56(29.3)$ \\
Dizziness or other CNS problem & 14 & 0 & 0 & 0 & 0 & 0 & $14(7.3)$ \\
Skin irritation & 4 & 1 & 0 & 6 & 2 & 1 & $14(7.3)$ \\
Shortness of breath & 7 & 2 & 1 & 0 & 0 & 1 & $11(5.8)$ \\
Other & 0 & 2 & 0 & 0 & 0 & 0 & $2(1.0)$ \\
Trauma & 0 & 1 & 0 & 0 & 0 & 0 & $1(0.5)$ \\
Burns & 0 & 0 & 0 & 0 & 0 & 1 & $1(0.5)$ \\
Heat stress & & & 0 & 0 & 0 & 0 \\
\hline
\end{tabular}

* Casualty categories: 1) employee, 2) member of general public, 3) professional firefighter, 4) firefighter (not specified), 5) employee (member of company response team), 6) student (when at school). 
Table 12. Events involving evacuation, by evacuation area, Poland, 2005

\begin{tabular}{lcr}
\hline \multicolumn{1}{c}{ Evacuation area } & $\begin{array}{c}\text { No. } \\
\text { events }\end{array}$ & $\%$ \\
\hline No criteria defined & 3 & 6.1 \\
Circle/radius & 4 & 8.2 \\
Downwind/downstream & 1 & 2.0 \\
Building(s) or affected part of building(s) & 32 & 65.3 \\
Circle and downwind/downstream & 2 & 4.1 \\
No information available & 7 & 14.3 \\
Total & 49 & 100.0 \\
\hline
\end{tabular}

Table 13. HSEES events, by restricted access area, Poland, 2005

\begin{tabular}{lrr}
\hline \multicolumn{1}{c}{ Restricted access area } & $\begin{array}{c}\text { No. } \\
\text { events }\end{array}$ & \multicolumn{1}{c}{$\%$} \\
\hline No restriction & 154 & 57.5 \\
Room & 18 & 6.7 \\
Wing/section of building & 21 & 7.8 \\
Building & 15 & 5.6 \\
Facility & 16 & 6.0 \\
Parking lot & 0 & 0.0 \\
Access route/road & 38 & 14.2 \\
Other adjacent areas & 6 & 2.2 \\
Total & 268 & 100.0 \\
\hline
\end{tabular}

or section of a building, a whole building or facility were comparable (respectively 6.7\%, 7.8\%, 5.6\%, and 6\%) (Table 13).

\section{DISCUSSION}

The database developed within the framework of the HSEES system contains records on chemical emergency incidents that are unique to Poland and the US. As such, it provides an opportunity to generate a variety of statistical analyses that are helpful in planning prevention activities aimed at reducing the harmful effects of chemicals spills. In the US, after an almost 20 years of operation of the HSEES system, a wide scope of prevention activities has been implemented. These activities include:
- presenting HSEES data to industries accounting for a significant number of chemical releases;

- providing HSEES data analysis to the state and local emergency planners to help them develop the most effective emergency plans, as well as appoint Hazardous Material Teams, gather necessary equipment and organize relevant training courses;

- providing data to establish and maintain protection areas for municipal water supply systems;

- distributing fact sheets among representatives of industry, responders, and environmental groups on the chemicals most frequently involved in chemical emergencies and causing the highest number of injuries [3-13].

What is also important, the whole HSEES protocol evolves to make the data analysis more effective in reaching the HSEES goals. The case definition used for the system purposes which read 'acute releases of hazardous substances that need to be cleaned up or neutralized according to federal, state, or local law, as well as threatened releases that result in a public health action such as an evacuation' has also been made more precise and now reads as 'acute releases as well as threatened releases of hazardous substances, in the amount equal or higher than 10 pounds/1 gallon (unless on the mandatory reporting list), that result in a public health action such as an evacuation' [2].

In Poland, the HSEES data started to be collected in January 2005; therefore, the public use of the results of data analysis and of the prevention activities differs significantly from that in the US where the system has been in operation since 1990's. Further data analysis is required before the preventive activities can be planned and organized on a national scale. Nevertheless, the 2005 data were used in Poland to prepare the first aid algorithms for firefighters as the primary responders to chemical emergencies and the group at the highest risk of injury. The substances for which the algorithms were worked out include mercury diiodide (CAS: 7774-29-0), potassium dichromate (CAS: 7778-50-9), hydrogen sulphide (CAS: 7783-06-4), ethylene oxide (CAS: 75-21-8), chlorine (CAS: 7782-50-5), hydrogen chloride (CAS: 7647-01-0), hydrogen chloride (\%) (WE 231-595-7), formaldehyde (CAS: 50-00-0), aluminium phosphide (CAS: 20859-73-8), phenol 
(CAS: 108-95-2), hydrazine (CAS: 302-01-2), sodium hydroxide (CAS: 1310-73-2), acetic acid (CAS: 64-19-7), nitric acid (CAS: 7697-37-2), sulphuric acid (CAS: 7664-93-9), orthophosphoric acid (CAS: 7664-38-2), butyric acid (CAS: 107-92-6), sodium hypochlorite (CAS: 7681-52-9), calcium hypochlorite (CAS: 7778-54-3), ammonia, aqueous solution (CAS: 1336-21-6).

As revealed by the technical report for 2005, some findings need clarification; these include the high number of mercury-related events, the high number of victims in educational services, and the ratio of fixed-facility to transportation-related events which is significantly different from that in the US. Considering the high number of mercury-related events, one can note that it is associated with numerous household incidents of mercury release from broken thermometers in 2005. In the reports for 2006 and 2007, this kind of events was excluded from analysis due to the insignificant amounts of mercury released this way. The high number of victims of the events in educational services in 2005 was mostly due to the intentional release of pepper gas by one of the students at a public school. The incident resulted in inhalation exposure of the students who fortunately experienced no severe injuries and were taken to hospital for observation. With regard to the differences between Poland and the US in the ratio of the fixed-facility to transportation-related events, Poland faces relatively more transportation-related events than does the US. The underlying reasons may be a different structure and size of the chemical industry as well as different geographical conditions and principles of administration. First of all, the Polish chemical industry has a much smaller market share in chemical industry worldwide. Moreover, its structure differs significantly — small and medium-size companies prevail, which makes this industry more scattered over the country and results in higher transportation needs. Furthermore, the road transportation system is used by foreign companies for cargo transit. Some chemical emergency incidents reported under HSEES are connected with the transit of hazardous chemicals through the territory of Poland. As the data collection within the HSEES system is ongoing in Poland, further analyses and health protection activities are envisaged.

\section{ACKNOWLEDGEMENTS}

Special acknowledgements to The Polish National HQ of the State Fire Service, in particular to Col. Dariusz Marczyński, Deputy Director of the Department of Civil Protection, and to the ATSDR Staff working on the HSEES project for a continuous support and effective cooperation.

\section{REFERENCES}

1. Hazardous Substances Emergency Events Surveillance System. FACT SHEET, January 13, 2005. Dept. of Health and Human Services, ATSDR, Atlanta. Available from: http:// www.atsdr.cdc.gov/HS/HSEES/.

2. Hazardous Substances Emergency Events Surveillance (HSEES). Protocol, March 2004. Division of Health Studies ATSDR, Atlanta: Department of Health and Human Services [cited 2008 June 14]. Available from: http://www.atsdr.cdc. gov/HS/HSEES/.

3. Hazardous Substances Emergency Events Surveillance (HSEES), Annual Report 1995. Atlanta: Department of Health and Human Services [cited 2008 June 14]. Available from: http://www.atsdr.cdc.gov/HS/HSEES/.

4. Hazardous Substances Emergency Events Surveillance (HSEES), Annual Report 1996. Atlanta: Department of Health and Human Services [cited 2008 June 14]. Available from: http://www.atsdr.cdc.gov/HS/HSEES/.

5. Hazardous Substances Emergency Events Surveillance (HSEES), Annual Report 1997. Atlanta: Department of Health and Human Services [cited 2008 June 14]. Available from: http://www.atsdr.cdc.gov/HS/HSEES/.

6. Hazardous Substances Emergency Events Surveillance (HSEES), Annual Report 1998. Atlanta: Department of Health and Human Services [cited 2008 June 14]. Available from: http://www.atsdr.cdc.gov/HS/HSEES/.

7. Hazardous Substances Emergency Events Surveillance (HSEES), Annual Report 1999-2000. Atlanta: Department of Health and Human Services [cited 2008 June 14]. Available from: http://www.atsdr.cdc.gov/HS/HSEES/.

8. Hazardous Substances Emergency Events Surveillance (HSEES), Annual Report 2001. Atlanta: Department of Health and Human Services [cited 2008 June 14]. Available from: http://www.atsdr.cdc.gov/HS/HSEES/. 
9. Hazardous Substances Emergency Events Surveillance (HSEES), Annual Report 2002. Atlanta: Department of Health and Human Services [cited 2008 June 14]. Available from: http://www.atsdr.cdc.gov/HS/HSEES/.

10. Hazardous Substances Emergency Events Surveillance (HSEES), Annual Report 2003. Atlanta: Department of Health and Human Services [cited 2008 June 14]. Available from: http://www.atsdr.cdc.gov/HS/HSEES/.

11. Hazardous Substances Emergency Events Surveillance (HSEES), Annual Report 2004. Atlanta: Department of
Health and Human Services [cited 2008 June 14]. Available from: http://www.atsdr.cdc.gov/HS/HSEES/.

12. Hazardous Substances Emergency Events Surveillance (HSEES), Four-Year Cumulative Report 1993-1997. Atlanta: Department of Health and Human Services [cited 2008 June 14]. Available from: http://www.atsdr.cdc.gov/HS/HSEES/.

13. Hazardous Substances Emergency Events Surveillance (HSEES), Four-Year Cumulative Report 1998-2001. Atlanta: Department of Health and Human Services [cited 2008 June 14]. Available from: http://www.atsdr.cdc.gov/HS/HSEES/. 